Portland State University

PDXScholar

Fall 2020

\title{
Exploratory Study of Obesogenic Commercial School Food Environments in the Portland Metropolitan Area
}

Sruthi Eapen

Portland State University

Follow this and additional works at: https://pdxscholar.library.pdx.edu/honorstheses

Part of the Food Studies Commons, and the Public Health Commons Let us know how access to this document benefits you.

Recommended Citation

Eapen, Sruthi, "Exploratory Study of Obesogenic Commercial School Food Environments in the Portland Metropolitan Area" (2020). University Honors Theses. Paper 943.

https://doi.org/10.15760/honors.966

This Thesis is brought to you for free and open access. It has been accepted for inclusion in University Honors Theses by an authorized administrator of PDXScholar. Please contact us if we can make this document more accessible: pdxscholar@pdx.edu. 
Exploratory Study of Obesogenic Commercial School Food Environments in the Portland

\title{
Metropolitan Area
}

By

\section{Sruthi Eapen}

\begin{abstract}
An undergraduate honors thesis submitted in partial fulfillment of the requirements for the degree of

Bachelors of Science

in

University Honors

and

Public Health Studies
\end{abstract}

Thesis Advisor

Betty Izumi, Ph.D., MPH, RD

Portland State University 


\begin{abstract}
Objective

The purpose of this exploratory research was to study commercial food environments around high schools in the Portland metropolitan area to explore the question: How do the economic, geographic, and racial demographics of public high schools in the Portland metropolitan area affect the prevalence and make-up of obesogenic commercial food environments surrounding these schools?
\end{abstract}

\title{
Methods
}

Commercial food environments within a $1 \mathrm{~km}$ radius of 35 public high schools in the Portland metropolitan area were surveyed. The "healthiness" of the environment was calculated by establishing a "Food Environment Score." This score was correlated with economic, geographic, and racial demographics obtained from the Oregon Department of Education (2018-2019) and the National Center for Education Statistics (2018) databases.

\section{Results}

There were significant relationships between the locale (urban to rural classification) of a school and the Food Environment Score $\left(\mathrm{R}^{2}\right.$ of 0.1131 , p-value of 0.0482$)$ and between the proportion of students who were multiracial and the Food Environment Score $\left(\mathrm{R}^{2}\right.$ of 0.1116 , p-value of 0.0497). There were no statistically significant correlations between other demographic variables and the Food Environment Score.

\section{Conclusion}

This exploratory research showed that urban school food environments may be healthier than rural school food environments, possibly due to the greater number of establishments in urban areas. It also showed that schools with greater proportions of multiracial students may have healthier surrounding food environments. However, future ethnographic and survey-based research must be done within schools to further study these observed relationships.

\section{Keywords}

Obesogenic environments, competitive school foods, commercial food environments, high school food environments 


\section{Introduction}

Obesity is prevalent in the United States, establishing a significant setting for diet-related chronic disease. Diet-related chronic disease affects individuals disproportionately due to the social determinants of health. Obesogenic food environments, which are environments with factors that lead to obesity, are one of these determinants (Timmerman et al., 2018). 13.7 million (18.5\%) of adolescents in the US are obese (Hales et al., 2017). Therefore, adolescent food environments are important to study; high school food environments are especially important given that students have more autonomy in their purchasing decisions. In 2010, "Smart Snacks" guidelines were implemented under the Healthy Hunger-Free Kids Act, providing regulation on competitive foods in school environments; however, these guidelines do not account for food options sold outside of the campus (USDA, 2019).

Students access outside commercial food options before and after school as well as during lunch at schools with open campus lunch (Austin et al., 2005). In the US, 25\% of high schools have open lunch policies, which allow students to obtain lunch from off-campus during lunch hours (Miura, 2009). Students with open campus policies are more likely to eat at fast-food restaurants during the week compared to students with closed campus policies (Neumark-Sztainer et al., 2005). Fast food options are often highly processed and offer little nutritional value. In a study done in Minnesota, when fast-food restaurants were within one mile of a school, students ate fewer fruits and vegetables, drank more soda, and were disproportionately overweight (Neumark-Sztainer et al., 2005). The school commercial food environment is not limited to fast-food restaurants. Among students living in urban areas, a significant amount of daily energy intake is purchased from stores near students' schools (Borradaile et al., 2009).

Previous research has established relationships between the proximity of commercial food environments to high schools and obesity outcomes (Davis \& Carpenter, 2009; Nixon \& Doud, 2011; Jackson County Health Dept., 2019). However, correlational relationships within the field of public health are complex; obesity outcomes are related to an interplay of multifactorial socioeconomic causes. Therefore, research regarding obesity must include an analysis of a variety of demographic variables. For example, the effects of obesogenic food environments are disproportionately experienced by minorities. Due to outside marketing targeting specific groups, low-income students as well as Black and Hispanic students disproportionately purchase unhealthy foods within the commercial food environment (Velazquez et al., 2017; Caprio et al., 2008).

In a meta-analysis done on world-wide, school-related, obesogenic environments, several demographic variables regarding the schools were studied in relation to proximity to commercial food options (Da Costa Peres et al., 2020). Da Costa Peres et al. (2020), highlights needed areas of further research, such as analyzing the types of establishments that make up the commercial school food environments. Therefore, this exploratory research attempts to delve deeper by building off of previous research on school food environments but with a focus on specifically 
categorizing elements within the commercial school food environment. Rather than focusing on obesity rates within various schools, this work looks at the obesogenic environment that could predispose adolescents to obesity. This research is valuable in that it focuses only on high school food environments and categorizes both the food options and the demographic variables of the schools. Additionally, this research offers a unique insight into obesogenic food environments around schools in the Portland metropolitan area. Specifically, it explores the question: How do the demographics of public high schools in the Portland metropolitan area affect the prevalence and make-up of obesogenic commercial food environments surrounding these schools?

The evidentiary archive used to formulate this research was curated from scholarly works within the discipline of public health. The discourse community consisting of public health scholars aims to highlight the intersectional effects of socioeconomic and geographic variables on health outcomes. These relationships are then used to inform public policy and interventions that will ultimately lead to improved societal health outcomes. This research will add to the discourse community by providing insight into the categorization of elements of the commercial school food environments in the Portland area.

The impact of this research involves contributing to an archive that could substantiate public policies. Public health research regarding school food environments has already led to policy changes internationally. For example, it is now illegal to sell unhealthy food within 200 meters of schools in South Korea after the "Special Act on Children's Dietary Life Safety Management Act," was enacted (Da Costa Peres et al., 2020). Research in public health supports policies that work toward ensuring that our population is healthier. There are no current policies in the United States regarding the sale of unhealthy food outside of school environments. However, these environments have the ability to influence health outcomes given their role in the nutritional choices high school students make. Therefore, this exploratory research will introduce further questions to inform policy that could improve health outcomes.

\section{Methods}

This study was conducted within the Portland metropolitan area, which consists of three counties: Washington, Multnomah, and Clackamas. Within each county, all public schools with a population of over 1,000 students were analyzed to standardize the data. The analysis involved two steps: analysis of the food environment and analysis of the demographics.

Regarding the commercial food environment, geospatial analysis of the commercial food environments within $1 \mathrm{~km}$ of each high school was conducted using Google Maps (Fig. 1). Using the zoom feature on Google Maps, the food establishments within the radius were counted (Fig. 2). An $800 \mathrm{~m}$ radius has been established in previous food environment research as the average distance that could be covered in a 10-minute walk (Austin et al., 2005). A 200 m increment was added to the radius within this methodology as a buffer. The Google Maps methodology used in this research is supported by ethnographic scholars. In research done on the validity of Google 
street view on ethnographic research, $90 \%$ of elements within food environments were consistent with in-person observed elements (Clarke et al., 2010).

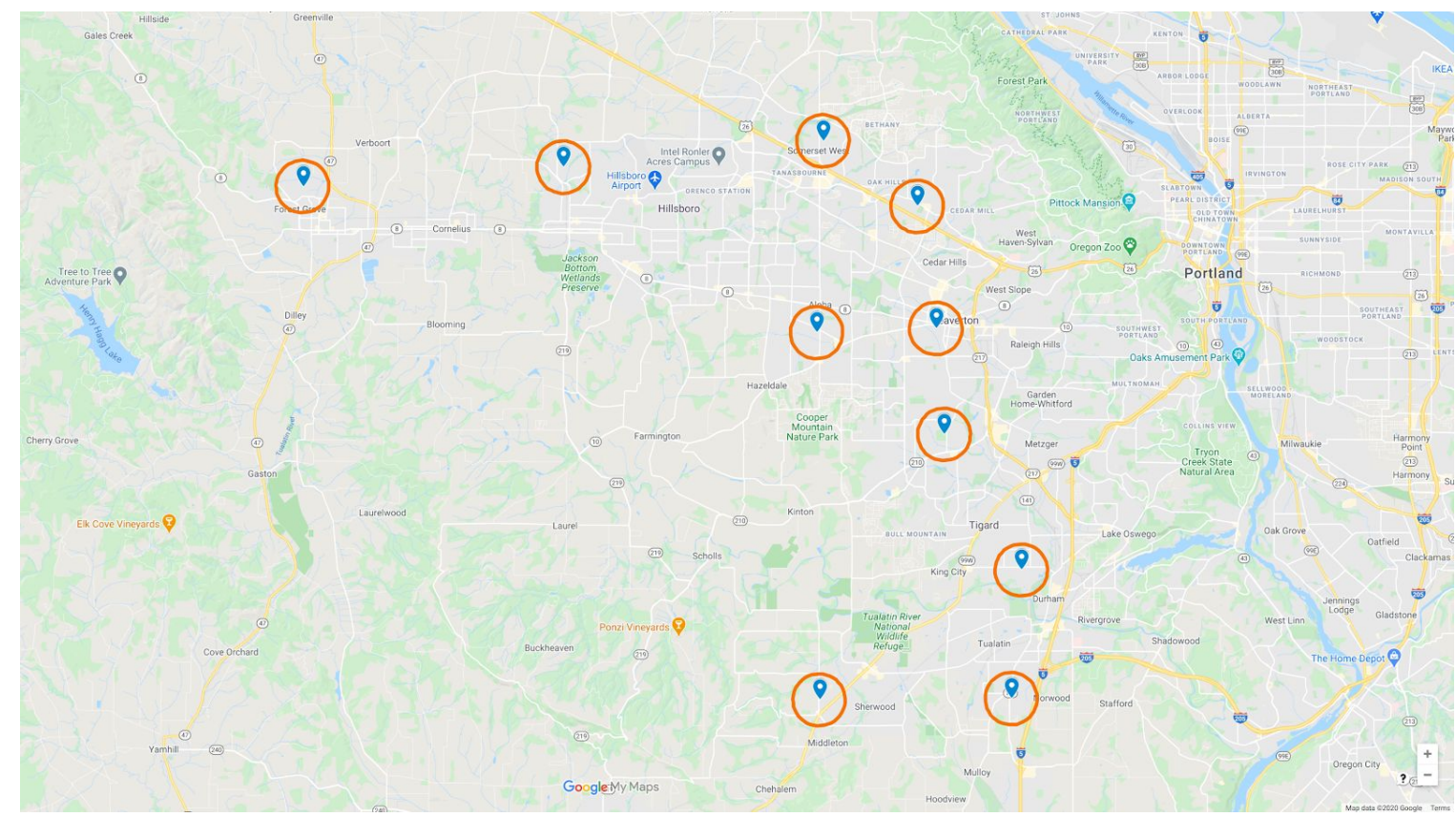

Figure 1. Depiction of $1 \mathrm{~km}$ Radii around Public High Schools in Washington County. Map Data: Google.

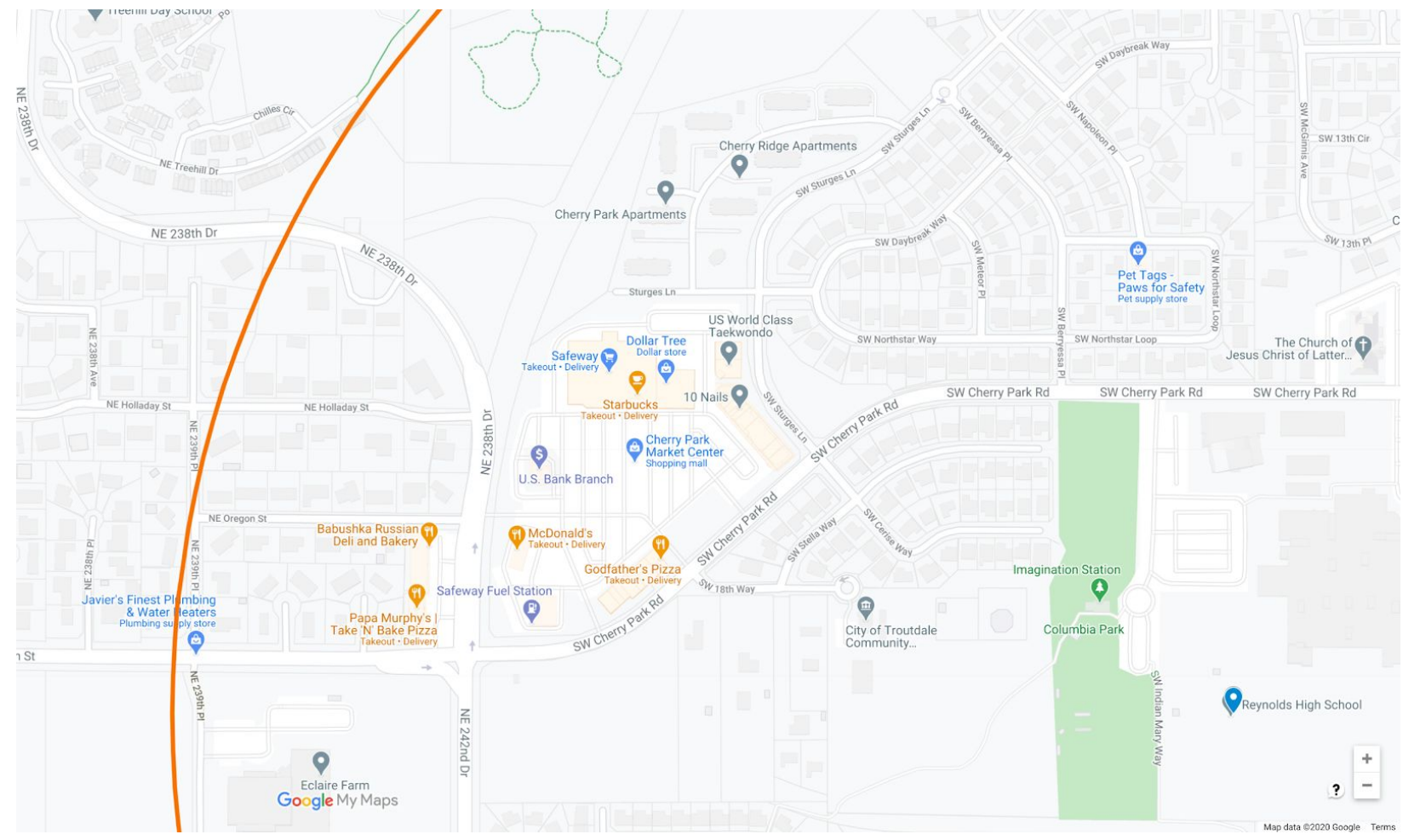

Figure 2. Zoomed in depiction of Radius around Reynolds High School. Map Data: Google. 


\section{Establishment Categorization}

The food establishments were categorized into five different types: commercial fast-food establishments, restaurants, low-nutrient high-energy dense establishments, convenience stores, and grocery stores. Commercial fast food establishments were primarily Quick Service Restaurant (QSR) established chain franchises. However, given that there is no established definition of fast-food (Jeffery et al., 2006), the following classifications from previous research were included: "quick service burger, quick service roast beef, and quick service pizza parlor" (Jeffery et al., 2006, methods para. 2) and "establishments which prepare pizza, barbecued chicken, and hamburgers for consumption either on or near the premises or for "take-home" consumption" (Chou et al., 2004, empirical implementation para. 7). Restaurants were classified as establishments that sell sit-down meals and did not meet fast-food establishment categorization. Low-nutrient high-energy dense establishments were classified as locations that primarily sell sweet desserts or drinks. Convenience stores were classified as smaller stores that sell a limited amount of food including packaged snacks and drinks (Morland et al., 2006). Grocery stores were classified as larger supermarkets that sell fresh produce and did not meet convenience store criteria. Table 1 below shows examples of each of these establishment types. Bars were not included within this study given that high school students are minors and would be unable to legally patronize these establishments. Similarly, farmer's markets were not included given that these markets are generally only available on weekends when students would not be in school.

Table 1. Examples of Food Establishment Categorization

\begin{tabular}{|l|l|}
\hline Food Establishment Category & Examples \\
\hline Fast Food & McDonald's, Burger King, Chick-fil-A \\
\hline Restaurants & Red Lobster, Mazatlan Mexican Restaurant \\
\hline Low-Nutrient, High Energy-Dense & Baskin Robbins, Bubble tea establishments, Starbucks \\
\hline Convenience Store & $7-11$, Plaid Pantry, Gas Station Stores \\
\hline Grocery Store & Safeway, Fred-Meyer, New Seasons \\
\hline
\end{tabular}

\section{Food Environment Score Calculation}

From the data on the counts of each of these establishments in the radius, each type of establishment was coded as "healthy" or "unhealthy." The justification of these classifications was derived from previous research. Eating at fast-food restaurants is associated with unhealthy eating whereas eating at sit-down restaurants is not (Close et al., 2016). Additionally, processed foods and foods high in salt, saturated fat, and excess sugar are associated with chronic disease (Fuhrman, 2018). Therefore, fast food restaurants and low-nutrient high-energy dense establishments were coded as unhealthy while regular restaurants were coded as healthy. Next, studies have shown that the prevalence of grocery stores is associated with less obesity while the prevalence of more convenience stores is associated with more obesity (Morland et al., 2006; Barnes et al., 2016). Therefore, grocery stores were coded as healthy and convenience stores 
were coded as unhealthy. A "Food Environment Score" was then calculated for each school using the formula: $\Sigma$ Healthy establishments $-\Sigma$ Unhealthy establishments . Therefore, higher Food Environment Scores were associated with healthier environments.

\section{Demographic Variables}

The demographic data was collected from the Oregon Department of Education database and the National Center for Education Statistics database. Three demographic variables were specifically studied: economic, geographic, and racial. The economic demographics were recorded based on the proportion of students within each school that qualify for reduced or free lunch from the Oregon Department of Education database. The geographic data was identified using the Locale Lookup feature provided by the National Center for Education Statistics and quantified by the coded "Locale Score" for analysis (Table 2) (Geverdt, 2019). This was further simplified into three locale categories: City, Suburb, and Rural/Town areas. The racial demographics were compiled from the Oregon Department of Education Database. Using the National Institute on Minority Health and Health Disparities research framework definition of racial minorities and the Oregon Department of Education data, American Indian, Asian, Black/African American, Hispanic, and Native Hawaiian/Pacific Islander groups were defined as minorities (Alvidrez et al., 2019). Given that there is no overall accepted framework for of multiracial categorization, this group was also included within the minority category given that many multiracial people experience race-based stress (Charmaraman, 2015).

Table 2. Locale Coding (From Geverdt, 2019)

\begin{tabular}{|l|l|}
\hline Locale & Score \\
\hline Large City & 11 \\
\hline Midsize City & 12 \\
\hline Small City & 13 \\
\hline Large Suburb & 21 \\
\hline Midsize Suburb & 22 \\
\hline Small Suburb & 23 \\
\hline Fringe Town & 31 \\
\hline Distant Town & 32 \\
\hline Remote Town & 33 \\
\hline Fringe Rural & 41 \\
\hline Distant Rural & 42 \\
\hline Remote Rural & 43 \\
\hline
\end{tabular}

\section{Data Analysis Methodology}

Each demographic data attribute (economic, geographic, and racial) was numerically quantified and individually plotted against the Food Environment Score associated with each school. Bivariate regression analysis was then conducted in Microsoft Excel for each relationship. From this analysis, the coefficient of determination was used to determine the linear 
fit of the data and the p-value was used to determine the significance ( $p$-value $<0.05$ ) of the relationship between the variables collected.

\section{Results}

Table 3 shows the counts of establishments in the commercial food environment around each school. Among the 35 schools which had a student population greater than 1,000 students, 12 were located in Washington County, 13 were located in Multnomah County and 10 were located in Clackamas County. The following high schools had no establishments within a $1 \mathrm{~km}$ radius: Hillsboro, Sherwood, Tualatin, Sam Barlow, Lakeridge, Oregon City, and Wilsonville (Table 3). However, these schools were included with the analysis given that they provide valuable information through the lack of establishments.

Table 4 shows the overall analysis of collected and compiled data. The calculated Food Environment Score of every school is shown in relation to the economic, geographic and racial demographic variables collected (Table 4). This data is also separated by county.

A significant correlation was observed between the locale of a school and its Food Environment Score ( $\mathrm{R}^{2}$ of 0.1131 with a p-value of 0.0482) (Table 6, Appendix Fig. 1). Through analysis of the complete data of all 35 schools, there was no significant correlation $\left(\mathrm{R}^{2}\right.$ of 0.0011 with a p-value of 0.8451 ), between socioeconomic status and the makeup of the surrounding food environment (Table 6, Appendix Fig. 2). There was also no significant correlation between the racial demographics of non-minority students and the makeup of the surrounding food environment ( $\mathrm{R}^{2}$ of 0.0000 with a p-value of 0.9900 ) (Table 6, Appendix Fig. 7). However, when further analysis was conducted by racial group, there was a significant relationship $\left(\mathrm{R}^{2}\right.$ of 0.1116 with a p-value of 0.0497) between the proportion of students who were multiracial and the Food Environment Score (Table 6, Appendix Fig. 6). There were no significant relationships found between any other racial group and the Food Environment Score.

Given that there was a significant correlation between locale and Food Environment Score, the overall data was further separated based on locale (city, suburb, and rural/town schools), as shown in Table 5. This data was subsequently individually analyzed for correlations between demographic variables (Table 6). There were no significant correlations found between the overall economic or racial demographics within these subsets based on location (Table 6, Appendix Figs. 3-5 and 8-10). 
Table 3. Categorization of Establishments by County

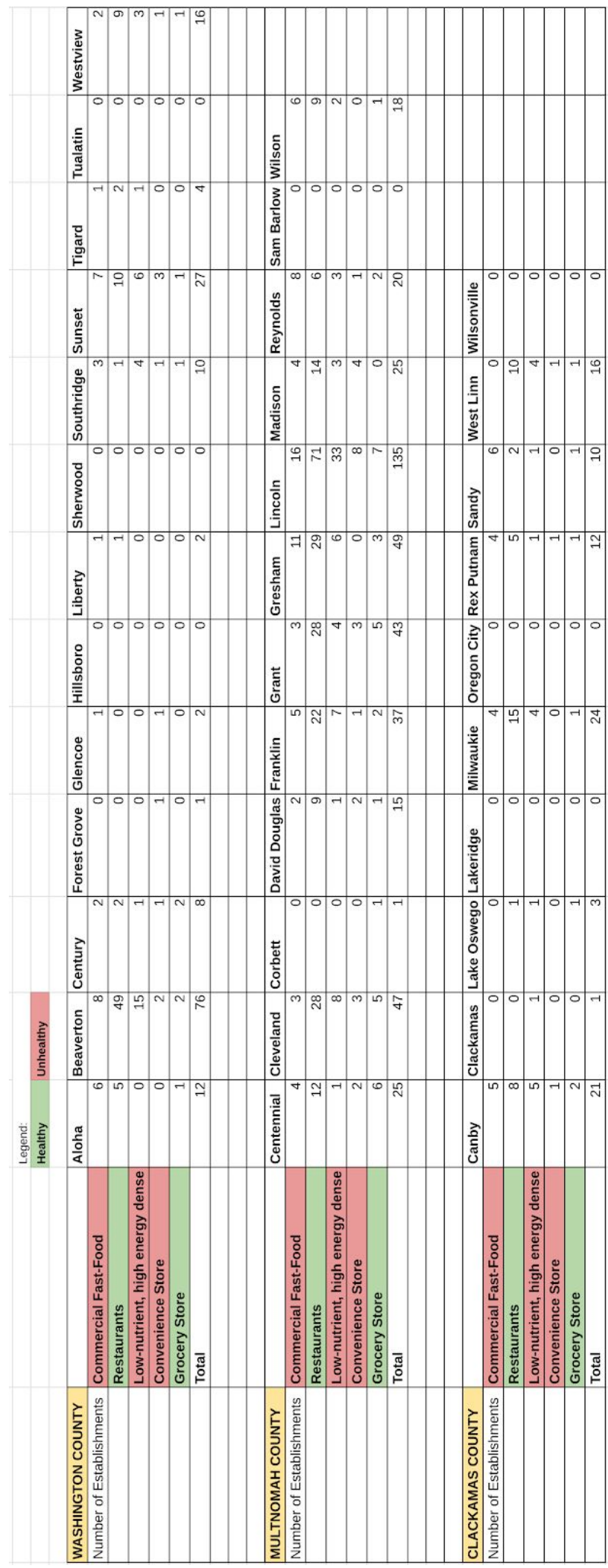


Table 4. Demographic Variables and Food Environment Score by County (Economic and racial data compiled from the Oregon Department of Education (2018-2019), geographic data compiled from the National Center for Education Statistics (2018))

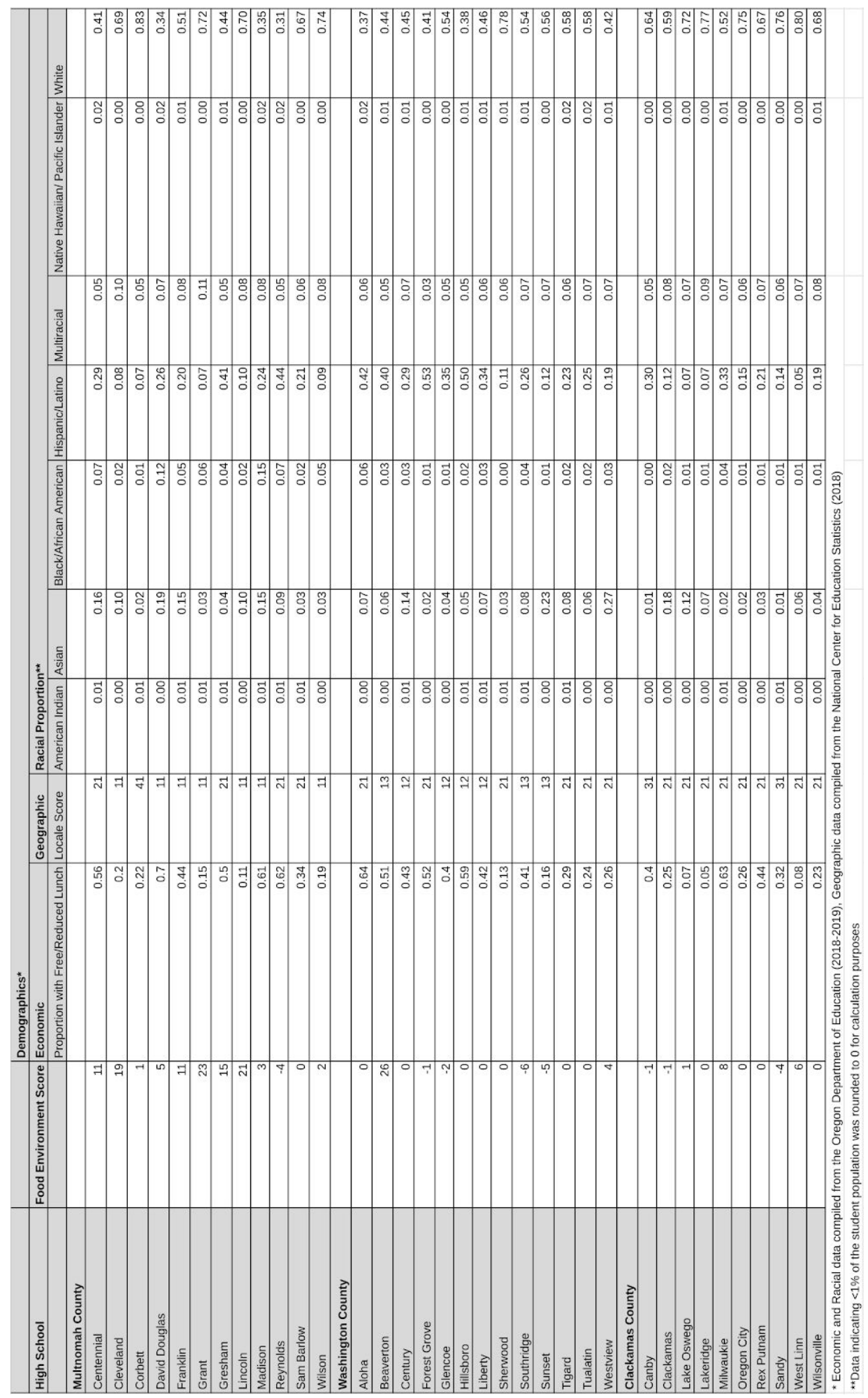


Eapen 10

Table 5. Demographic Variables and Food Environment Score by Locale (Economic and racial data compiled from the Oregon Department of Education (2018-2019), geographic data compiled from the National Center for Education Statistics (2018))

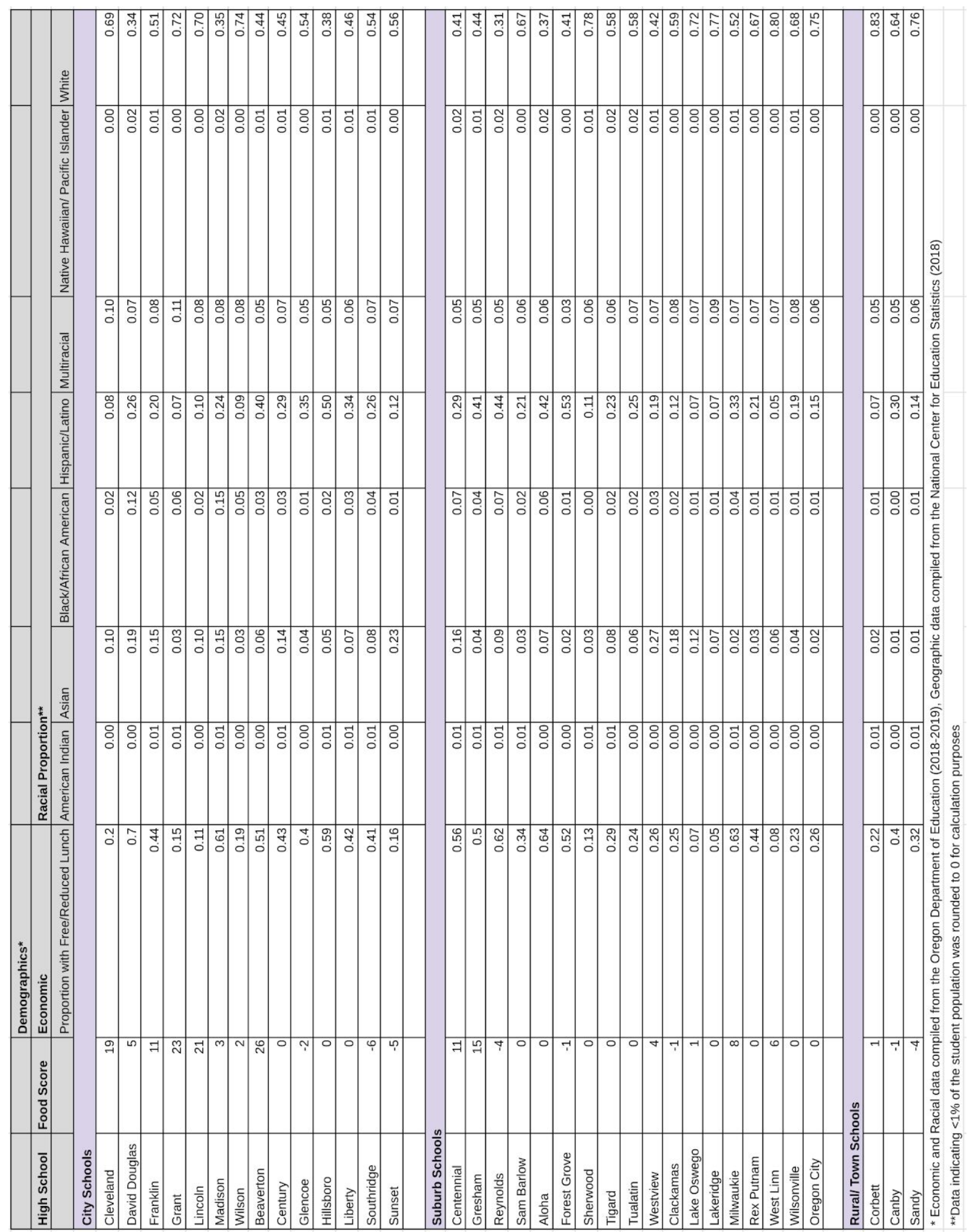


Table 6. Regression Analysis of Demographic Variables and Food Environment Score (Economic and racial data compiled from the Oregon Department of Education (2018-2019), geographic data compiled from the National Center for Education Statistics (2018))

\begin{tabular}{|c|c|c|}
\hline \multicolumn{3}{|c|}{ Regression Analysis (significant p-values bolded) } \\
\hline & R-squared & P-value \\
\hline \multicolumn{3}{|c|}{ Locale vs Food Environment Score } \\
\hline & 0.1131 & 0.0482 \\
\hline \multicolumn{3}{|c|}{ Free/Reduced Lunch Proportion vs Food Environment Score } \\
\hline All Schools & 0.0011 & 0.8451 \\
\hline City Schools & 0.0781 & 0.3331 \\
\hline Suburb Schools & 0.0534 & 0.3564 \\
\hline Rural/Town Schools & 0.2071 & 0.6991 \\
\hline \multicolumn{3}{|c|}{ Proportion of non-minorities vs Food Environment Score } \\
\hline All Schools & 0.0000 & 0.9900 \\
\hline City Schools & 0.1319 & 0.2019 \\
\hline Suburb Schools & 0.0359 & 0.4511 \\
\hline Rural/Town Schools & 0.0650 & 0.8358 \\
\hline \multicolumn{3}{|c|}{ Further Breakdown of minority groups vs Food Environment Score } \\
\hline American Indian & 0.0003 & 0.9236 \\
\hline Asian & 0.0005 & 0.9019 \\
\hline Black/African American & 0.0352 & 0.2807 \\
\hline Hispanic/Latino & 0.0085 & 0.5984 \\
\hline Multiracial & 0.1116 & 0.0497 \\
\hline Native Hawaiian/ Pacific Islander & 0.0008 & 0.8690 \\
\hline
\end{tabular}

\section{Discussion}

The regression analysis showed a significant negative correlation between Food Environment Score and Locale Score; suggesting that, in the Portland metropolitan area, more urbanized areas may have healthier food environments. The relationship could possibly be due to the increased number of establishments in cities compared to rural areas. Rural areas had an average of 8 establishments, suburban areas had an average of 10.7 establishments, and city areas had an average of 30.9 establishments. More establishments may indicate healthier options overall. However, this is an area that requires further research. Within these locales, the average percentage of students who qualified for free or reduced lunch were roughly constant within the range of (0.30-0.38). Therefore, the socioeconomic status of the cities compared to rural areas cannot likely explain this difference. From this exploratory research, the geographic locale of the commercial school food environment was most indicative of its relative healthiness. Geographic locale is a multivariate descriptor that is influenced by multiple interconnected factors including 
business interests, historical factors, as well as socioeconomic and racial demographics. Therefore, this research highlights the need for future research specifically into the locale of food environments in the Portland metropolitan area.

There was a significant positive correlation between the proportion of students who were multiracial and the Food Environment Score, suggesting that schools with more multiracial students may have healthier surrounding food environments. There were no other statistically significant correlations within the racial demographics. Given the lack of previous research on multiracial students and its isolated statistical significance compared to other racial minority groups, this relationship must be explored further in future research to establish possible reasoning (Charmaraman et al., 2014). There were no significant correlations between the Food Environment Score and economic demographics, even when the data was separated by locale. This could be due to the diversity within high school settings. High schools are large establishments that many neighborhoods feed into. These neighborhoods are not homogeneous, increasing the variability in the student population. This variability may lead to insignificant findings given that direct associations cannot be drawn. Additionally, the small sample size within this exploratory study of Portland metropolitan high schools may limit the accuracy of the correlational significance between these variables. However, this does not imply that there are not economic or racial disparities in how unhealthy foods are advertised as demonstrated in previous research (Velazquez et al., 2017; Caprio et al., 2008). This research on the makeup of the school food environment does not reflect the purchasing patterns of students that patronize the establishments. Future ethnographic studies must be conducted to study this further.

\section{Strengths and Limitations}

A key strength of this exploratory study is the utilization of Google Maps technology as a data collection method. With the COVID-19 pandemic exposing the need for remote research methodologies, this work expands the body of research using Google Maps technology to public health quantitative research. Another strength of this work is the categorization of commercial school food environment establishments. Previous research has studied the food environments either by focusing on specific types of establishments or recording overall counts of food establishments (Da Costa Peres et al., 2020). This research introduces a unique framework for categorizing food establishments. Future research must include more granular definitions of these categories for further comparison. This work is valuable through its study of diverse metropolitan high school environments. Concepts in the field of public health research are multivariate and interconnected. Therefore, this research is strengthened by the incorporation of multiple demographic variables.

This work also has limitations that should be addressed through future research. Although two statistically significant $p$-values ( $p$-value $<0.05$ ) were found, these values were both very close to 0.05 (0.0482 and 0.0497), and therefore are not highly statistically significant at the level of $p$-value $<0.01$. The small sample size of this research is important to note in conjunction with these results given that the findings, while statistically significant, may not imply a real 
relationship (Leppink et al., 2016). Further research must be done to truly draw conclusions regarding these variables. This exploratory research has highlighted many areas of methodological improvement for future similar studies given its limitations. While the use of Google Maps technology is a strength of this research, it is also a limitation. Food establishments not registered on Google Maps, establishments that are newly opened, and establishments that have closed but are still present on the map may hinder the accuracy of the data. Similarly, only primarily food establishments were counted. Other establishments within $1 \mathrm{~km}$ of high schools such as movie theatres may also sell food. However, since they were not primarily food establishments, they did not show up as a food establishment on Google Maps. Next, the $1 \mathrm{~km}$ radius used within this study is generalized and may not be applicable to all schools. For example, students at Lincoln High School, located in downtown Portland, might have easier access to public transit options that would allow more of the students to travel further than the 1 $\mathrm{km}$ walking radius. Similarly, some schools may have more students with access to cars, further increasing the radius of the food environment. Next, in this methodology, the economic demographic was calculated using the proportion of students who qualified for free or reduced lunch from the Oregon Department of Education (2018-2019) database. However, other variables such as the median income of the school may offer more robust insight into this demographic variable in relation to the food environment surrounding the school. Another limitation of this research is the small sample size which limits the accuracy of the findings. Using data from high schools from other metropolitan areas similar to Portland could increase the sample size. Elementary and middle schools from the Portland metropolitan area could also be used to increase the sample size for future research.

\section{Specific Future Areas of Research}

This exploratory research has highlighted many areas for future research on commercial food environments around schools. The prevalence of food establishments around schools is not the only form of advertisement that students are exposed to. Future research should involve ethnographic studies of other aspects of food advertisement within school areas such as physical advertisement signs on school campuses, food-establishment sponsored events at the school, and advertising deals within the competitive school food environment. Another area of research involves reviewing open campus lunch policies in relation to the outside commercial school food environment.

Future research should involve ethnographic in-school studies including interviews and surveys. This way, the student behavior in the commercial school food environment could be matched with environmental studies such as this one. This could include surveying students patronizing habits in relation to demographic variables and perceptions of advertising. It could also involve interviews with the staff at the establishments within the school food environment. Conducting this ethnographic research will allow for further conclusions to be drawn regarding the statistically significant correlations found between the proportion of students who are 
multiracial and the Food Environment Score and between locale and the Food Environment Score.

To complement the Google Maps based research, walk-through audits of the food environments could be conducted to ensure the accuracy of the Google Maps research. More specific definitions of "healthy" and "unhealthy" establishments must be developed. For example, previous research indicates that convenience stores are less healthy compared to grocery stores (Morland et al., 2006; Barnes et al., 2016). However, there are an increasing number of convenience health food stores that may qualify as healthy based on in-person audits of the foods they sell. Similarly, sit-down restaurants can be further categorized as healthy or unhealthy based on the nutritional content of the foods they sell.

Through an exploratory study on commercial high school food environments in the Portland metropolitan area, this research has proposed methodology and identified many aspects to study further. Given the multivariate nature of public health research, tackling broad issues like adolescent obesity must be approached from many angles. Understanding this issue will require better insight into these multivariate relationships.

\section{Acknowledgments}

I would like to thank my advisor, Dr. Betty Izumi, for her time and support throughout the research process.

I would also like to thank the Portland State University Honors College for providing me with resources and support throughout this undergraduate thesis endeavor.

\section{References}

Alvidrez, J., Castille, D., Laude-Sharp, M., Rosario, A., \& Tabor, D. (2019). The National Institute on Minority Health and Health Disparities Research Framework. American journal of public health, 109(S1), S16-S20. https://doi.org/10.2105/AJPH.2018.304883

Austin, S. Bryn, Melly, Steven J., Sanchez, Brisa N., Patel, Aarti, Buka, Stephen, \& Gortmaker, Steven L. (2005). Clustering of fast-food restaurants around schools: A novel application of spatial statistics to the study of food environments. The American Journal of Public Health, 95(9), 1575-15781.

Barnes, T. L., Pelletier, J. E., Erickson, D. J., Caspi, C. E., Harnack, L. J., \& Laska, M. N. (2016). Healthfulness of Foods Advertised in Small and Nontraditional Urban Stores in Minneapolis-St. Paul, Minnesota, 2014. Preventing chronic disease, 13, E153. https://doi.org/10.5888/pcd13.160149 
Borradaile, K. E., Sherman, S., Vander Veur, S. S., McCoy, T., Sandoval, B., Nachmani, J., Karpyn, A., \& Foster, G. D. (2009). Snacking in children: the role of urban corner stores. Pediatrics, 124(5), 1293-1298. https://doi.org/10.1542/peds.2009-0964

Caprio, S., Daniels, S. R., Drewnowski, A., Kaufman, F. R., Palinkas, L. A., Rosenbloom, A. L., \& Schwimmer, J. B. (2008). Influence of race, ethnicity, and culture on childhood obesity: implications for prevention and treatment: a consensus statement of ShapingAmerica's Health and the Obesity Society. Diabetes care, 31(11), 2211-2221. https://doi.org/10.2337/dc08-9024

Charmaraman, L., Woo, M., Quach, A., \& Erkut, S. (2014). How have researchers studied multiracial populations? A content and methodological review of 20 years of research. Cultural diversity \& ethnic minority psychology, 20(3), 336-352. https://doi.org/10.1037/a0035437

Chou, Shin-Yi, Grossman, Michael, \& Saffer, Henry. (2004). An economic analysis of adult obesity: results from the Behavioral Risk Factor Surveillance System. Journal of Health Economics, 23(3), 565-587. https://doi.org/10.1016/j.jhealeco.2003.10.003

Clarke P, Ailshire J, Melendez R, Bader M, Morenoff J. (2010). Using Google Earth to conduct a neighborhood audit: reliability of a virtual audit instrument. Health \& Place 2010,16(6):1224-1229. doi:10.1016/j.healthplace.2010.08.007 10.1016/j.healthplace.2010.08.007

Close, Michael A., MS, Lytle, Leslie A., PhD, \& Viera, Anthony J., MD, MPH. (2016). Is frequency of fast food and sit-down restaurant eating occasions differentially associated with less healthful eating habits? Preventive Medicine Reports, 4, 574-577. https://doi.org/10.1016/j.pmedr.2016.10.011

Da Costa Peres, C., Gardone, D., Mendes, L., Costa, B., Duarte, C., \& Pessoa, M. (2020). Retail food environment around schools and overweight: A systematic review. Nutrition Reviews, Nutrition reviews.

Davis, B., \& Carpenter, C. (2009). Proximity of fast-food restaurants to schools and adolescent obesity. American journal of public health, 99(3), 505-510. https://doi.org/10.2105/AJPH.2008.137638

Fuhrman J. (2018). The Hidden Dangers of Fast and Processed Food. American journal of lifestyle medicine, 12(5), 375-381. https://doi.org/10.1177/1559827618766483 
Geverdt, D. (2019). Education Demographic and Geographic Estimates Program (EDGE): Locale Boundaries File Documentation, 2017 (NCES 2018-115). U.S. Department of Education. Washington, DC: National Center for Education Statistics. Retrieved [date] from http://nces.ed.gov/pubsearch.

Google. (n.d) [Google Maps of the Portland Metropolitan Area]. Retrieved September 1, 2020, from https://www.google.com/maps.

Hales CM, Carroll MD, Fryar CD, Ogden CL. (2017). Prevalence of obesity among adults and youth: United States, 2015-2016. NCHS data brief, no 288. Hyattsville, MD: National Center for Health Statistics.

Jackson County Health Department. (2019). Proximity of Fast Food Restaurants to Schools in East Jackson County. Retrieved from https://jacohd.org/files/health-reports/youth-fast-food-report.pdf

Jeffery, R.W., Baxter, J., McGuire, M. et al. (2006). Are fast food restaurants an environmental risk factor for obesity?. Int J Behav Nutr Phys Act 3, 2. https://doi.org/10.1186/1479-5868-3-2

Leppink, J., Winston, K., \& O'Sullivan, P. (2016). Statistical significance does not imply a real effect. Perspectives on medical education, 5(2), 122-124. https://doi.org/10.1007/s40037-016-0256-6

Miura, M. (2009). Off the Map: Extracurricular School Food: Open Campus Lunch. Public Health Advocacy Institute.https://www.phaionline.org/wp-content/uploa ds/2009/04/otm_open_campus_lunch.pdf

Morland K, Diez Roux AV, Wing S. (2006). Supermarkets, other food stores, and obesity: the atherosclerosis risk in communities study. Am J Prev Med. 30(4):333-9. doi: 10.1016/j.amepre.2005.11.003. PMID: 16530621.

National Center for Education Statistics. (2018). Locale Lookup. Institute of Education Sciences. https://nces.ed.gov/programs/maped/LocaleLookup/

Neumark-Sztainer, D., French, S.A., Hannan, P.J. et al. (2005). School lunch and snacking patterns among high school students: Associations with school food environment and policies. Int J Behav Nutr Phys Act 2, 14 . https://doi.org/10.1186/1479-5868-2-14

Nixon, H., \& Doud, L. (2011). Do Fast Food Restaurants Cluster Around High Schools? A 
Geospatial Analysis of Proximity of Fast Food Restaurants to High Schools and the Connection to Childhood Obesity Rates. The Journal of Agriculture, Food Systems, and Community Development, 2, 181-194.

Oregon Department of Education. (2018-2019). School Profiles.

https://www.ode.state.or.us/data/reportcard/ReportList.aspx

Timmermans, J., Dijkstra, C., Kamphuis, C., Huitink, M., van der Zee, E., \& Poelman, M. (2018). 'Obesogenic' School Food Environments? An Urban Case Study in The Netherlands. International journal of environmental research and public health, 15(4), 619. https://doi.org/10.3390/ijerph15040619

USDA. (2019) A Guide to Smart Snacks in Schools. Fns-prod.azureedge.net. Retrieved from https://fns-prod.azureedge.net/sites/default/files/resource-files/USDASmartSnacks_508_6 2019.pdf

Velazquez, C. E., Black, J. L., \& Potvin Kent, M. (2017). Food and Beverage Marketing in Schools: A Review of the Evidence. International journal of environmental research and public health, 14(9), 1054. https://doi.org/10.3390/ijerph14091054 


\section{Appendix}

\section{Locale Demographic}

All Schools: Food Environment Score vs Locale Score

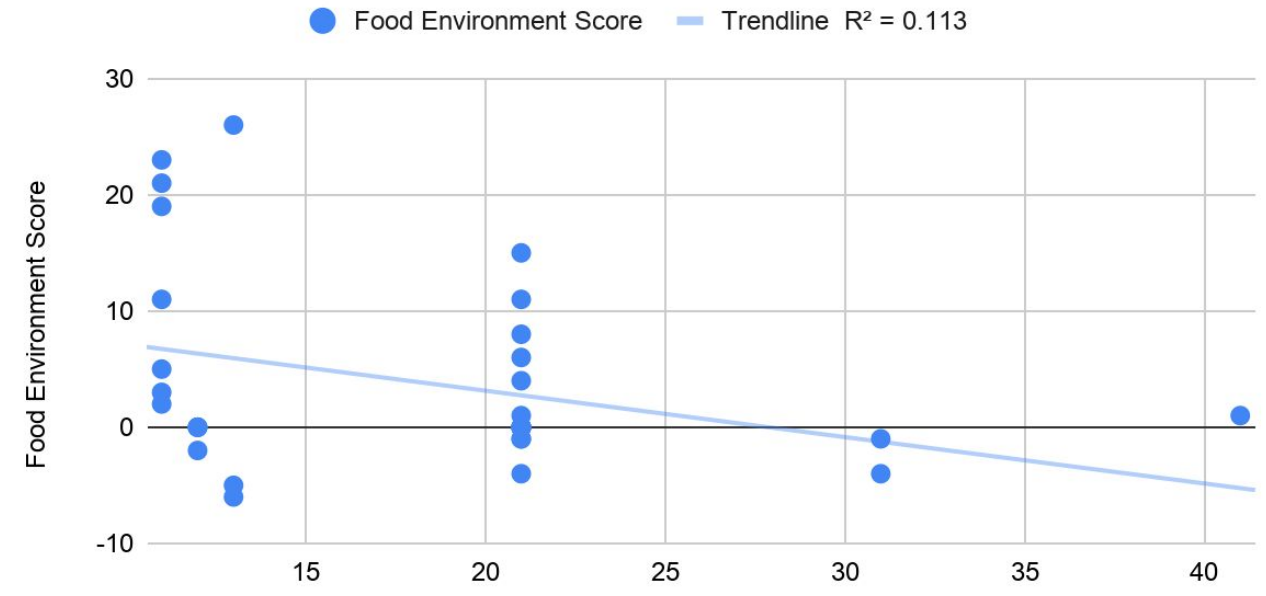

Locale Score (National Center for Education Statistics, 2018)

Figure 1. Graph of Food Environment Score vs Locale Score

\section{Economic Demographic}

All Schools: Food Environment Score vs. Proportion of Students who Qualify for Free/Reduced Lunch

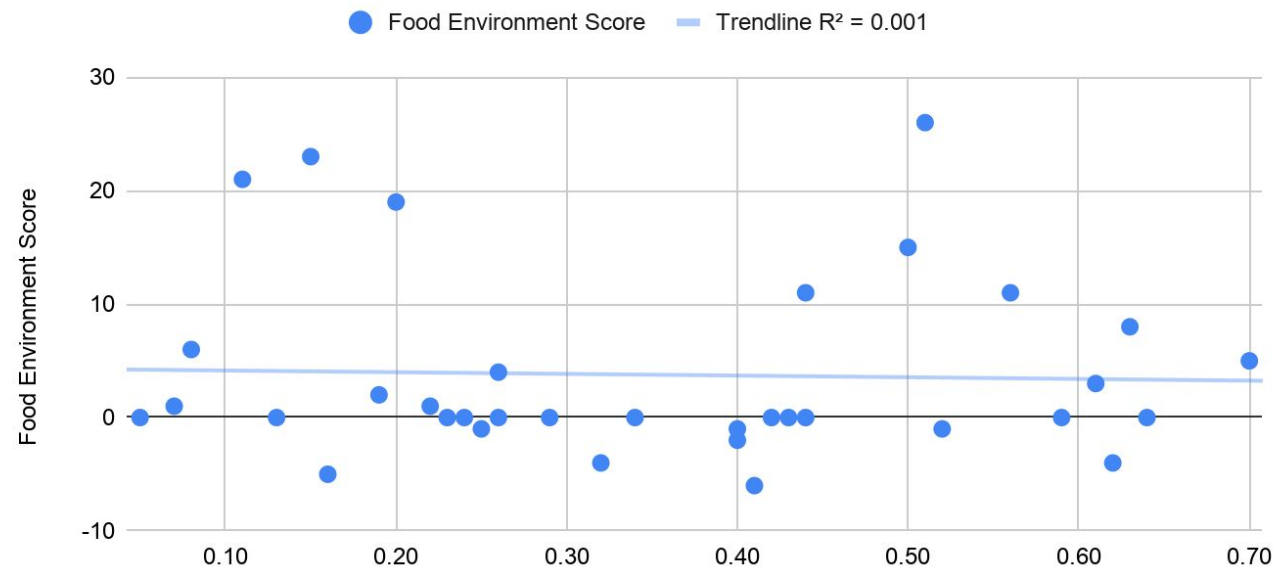

Proportion of Students who Qualify for Reduced Lunch (Oregon Department of Education, 2018-2019)

Figure 2. Graph of Food Environment Score vs Proportion of Students who Qualify for Free or Reduced Lunch in All Schools 
City Schools: Food Environment Score vs. Proportion of Students who Qualify for Free/Reduced Lunch

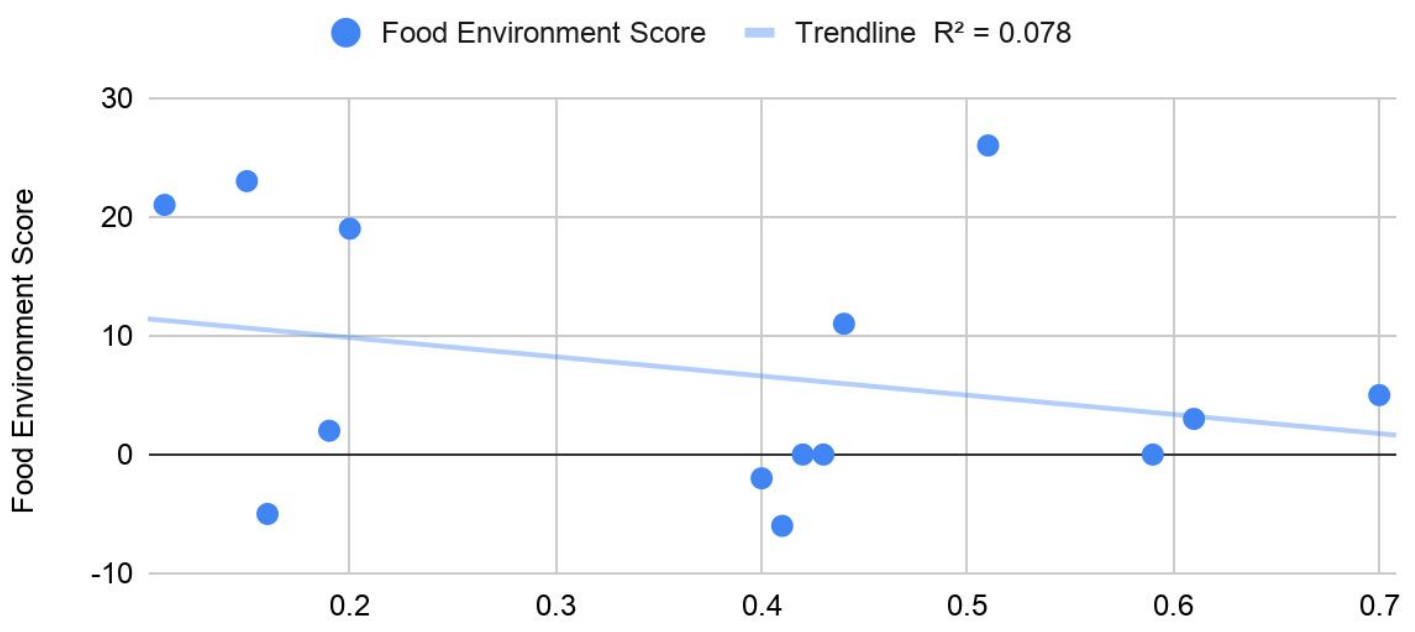

Proportion of Students who Qualify for Reduced Lunch (Oregon Department of Education, 2018-2019)

Figure 3. Graph of Food Environment Score vs Proportion of Students who Qualify for Free or Reduced Lunch in City Schools

Suburb Schools: Food Environment Score vs. Proportion of Students who Qualify for Free/Reduced Lunch

Food Environment Score $=$ Trendline $\mathrm{R}^{2}=0.053$

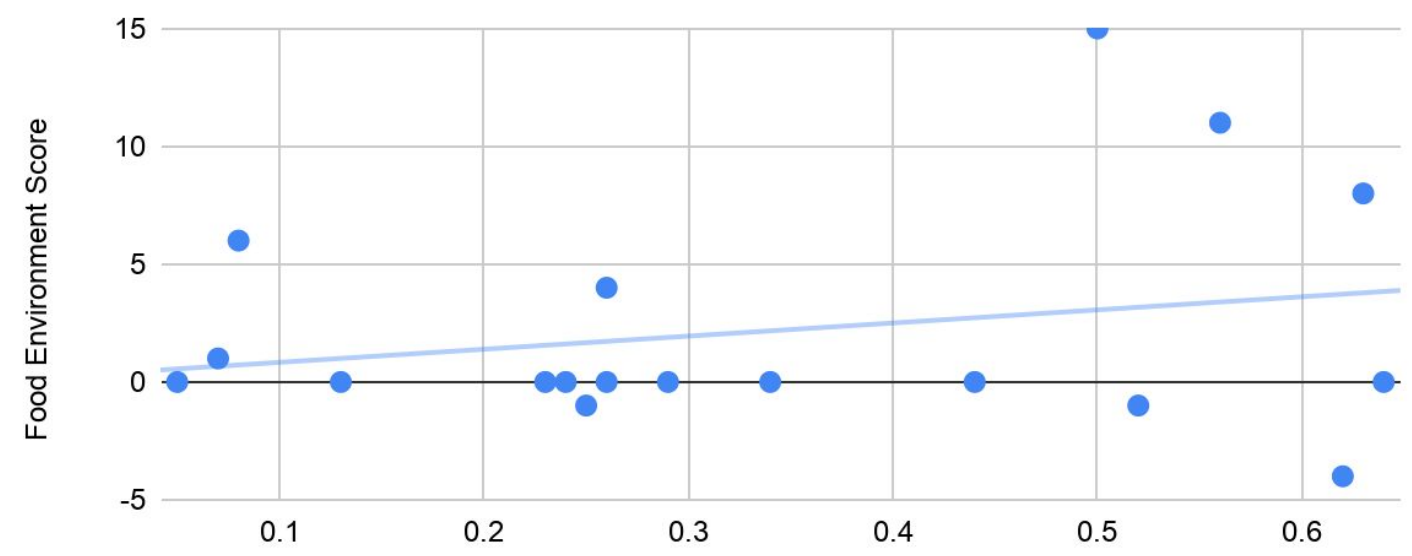

Proportion of Students who Qualify for Reduced Lunch (Oregon Department of Education, 2018-2019)

Figure 4. Graph of Food Environment Score vs Proportion of Students who Qualify for Free or Reduced Lunch in Suburb Schools 
Rural/Town Schools: Food Environment Score vs. Proportion of Students who Qualify for Free/Reduced Lunch

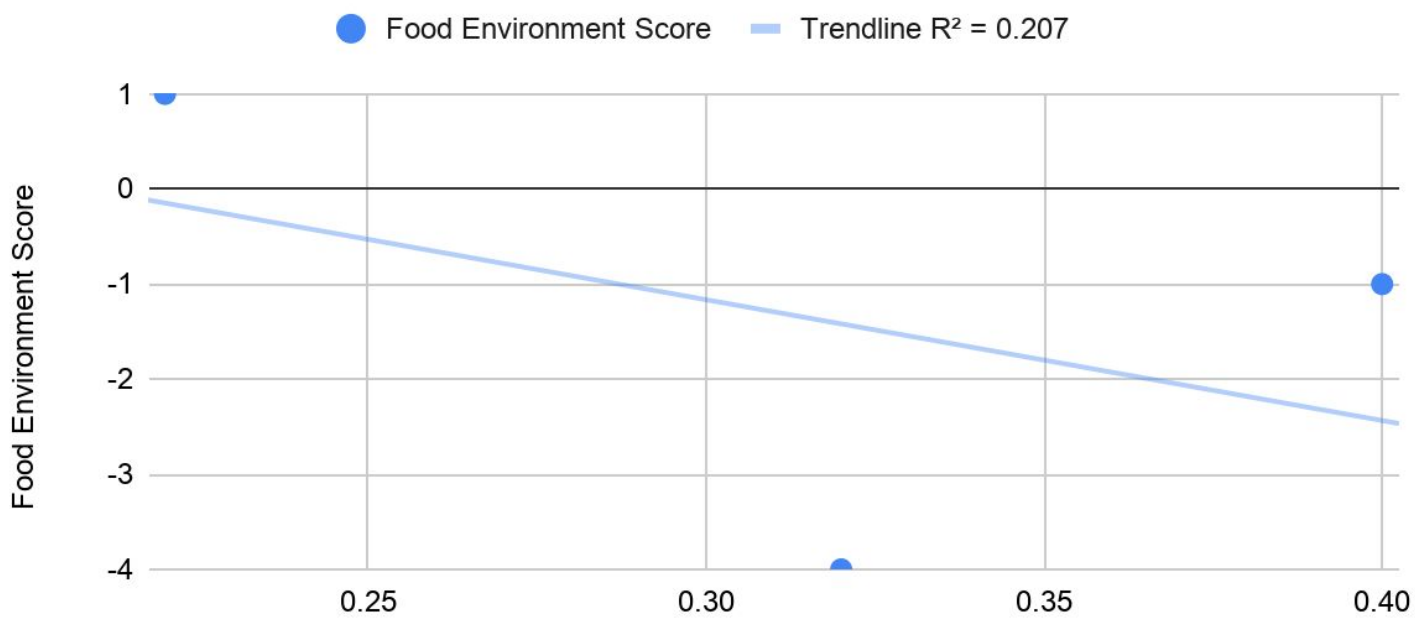

Proportion of Students who Qualify for Reduced Lunch (Oregon Department of Education, 2018-2019)

Figure 5. Graph of Food Environment Score vs Proportion of Students who Qualify for Free or Reduced Lunch in Rural/Town Schools

\section{Racial Demographic}

Racial Demographic Data vs Food Environment Score

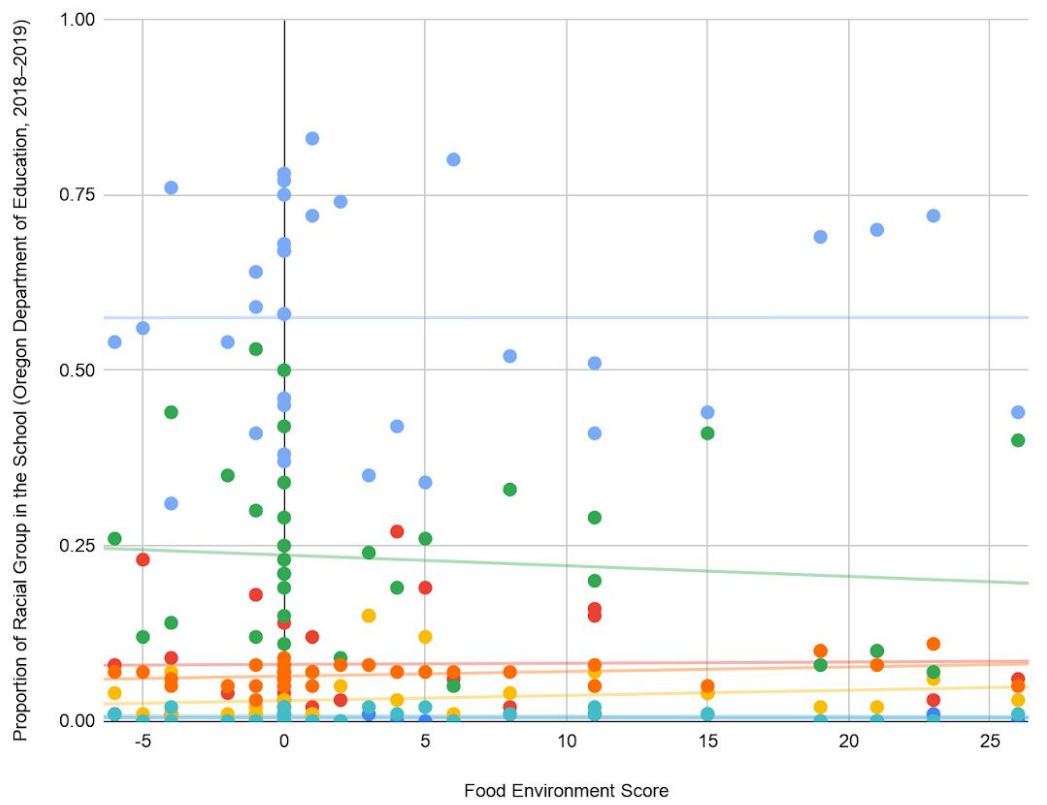

- American Indian

- Trendline for American Indian $\mathrm{R}^{2}=0$

- Asian

- Trendline for Asian $\mathrm{R}^{2}=0$

Black/African American

- Trendline for Black/African American $\mathrm{R}^{2}=$ 0.035

- Hispanic/Latino

- Trendline for Hispanic/Latino $R^{2}=0.008$

Multiracial

- Trendline for Multiracial $R^{2}=0.112$

Native Hawaiian/ Pacific Islander

Trendline for Native Hawailian/ Pacific

Islander $\mathrm{R}^{2}=0.001$

White

- Trendline for White $\mathrm{R}^{2}=0$

Figure 6. Graph of Food Environment Score vs Racial Makeup of All Schools 


\section{All Schools: Food Environment Score vs. Proportion of Students that are non-minorities}

Food Environment Score $=$ Trendline for Food Environment Score $\mathrm{R}^{2}=0$

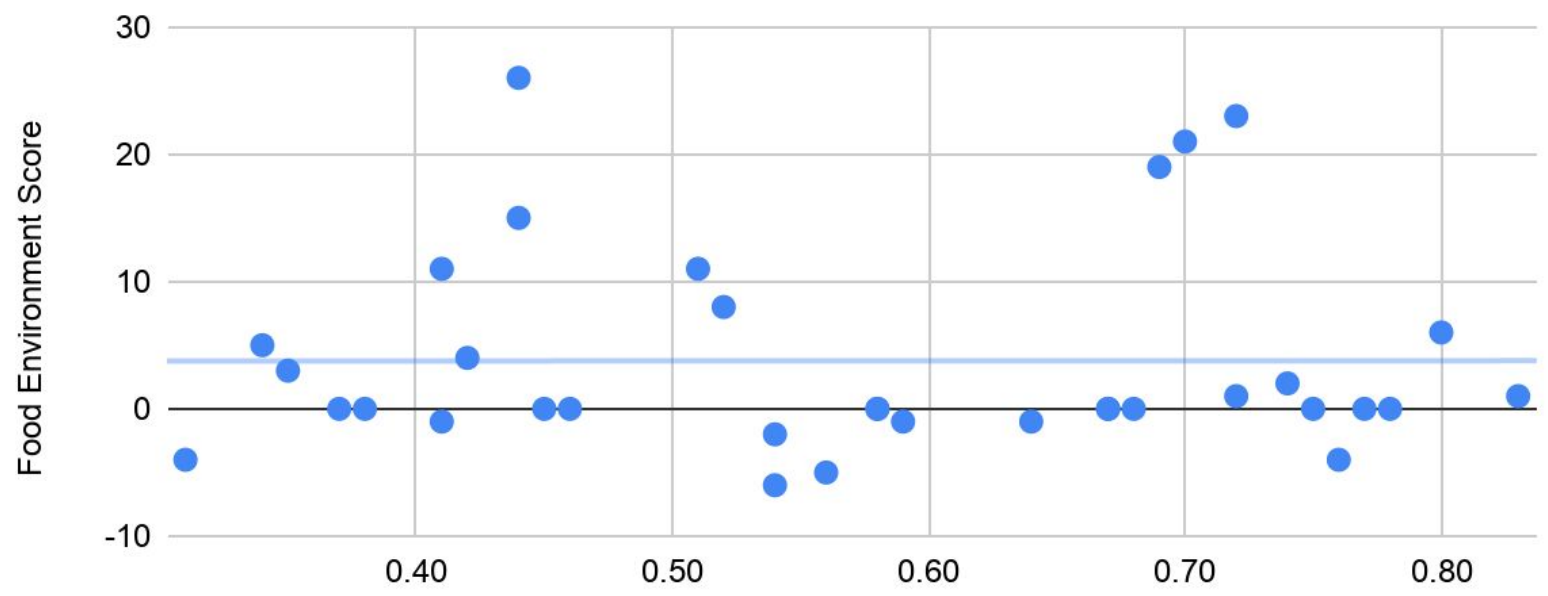

Proportion of Students that are non-minorities (Oregon Department of Education, 2018-2019)

Figure 7. Graph of Food Environment Score vs Proportion of Students who are Non-Minorities in All Schools

City Schools: Food Environment Score vs. Proportion of Students that are non-minorities

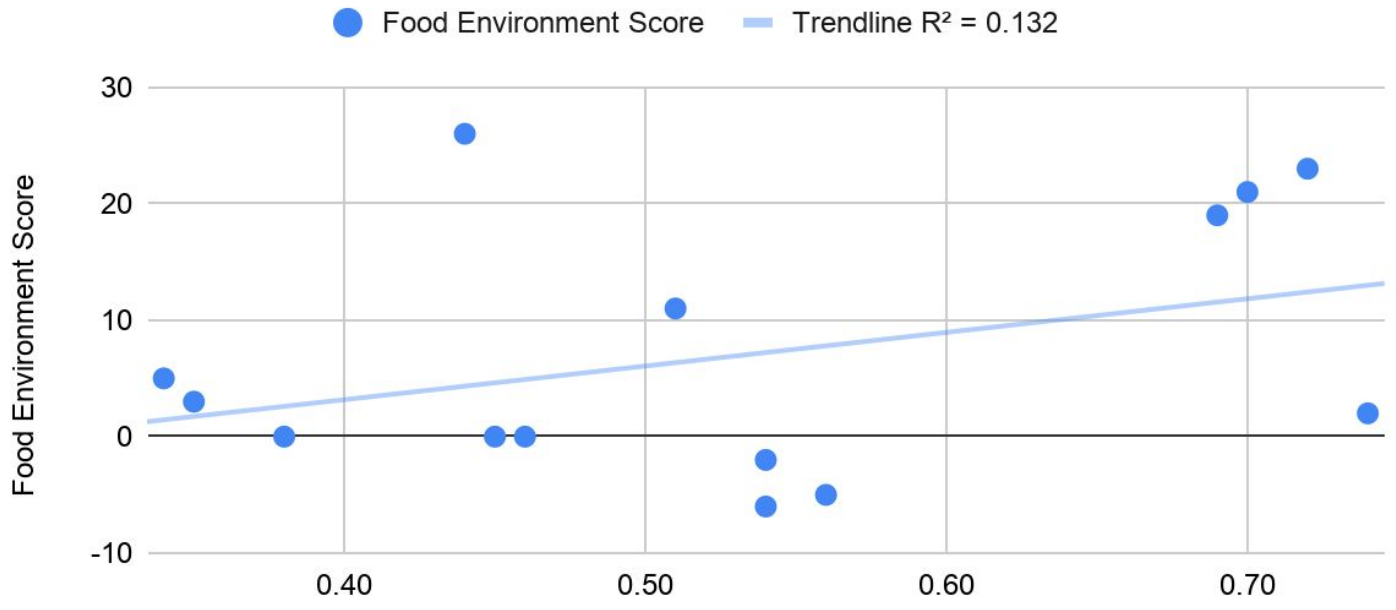

Proportion of Students that are non-minorities (Oregon Department of Education, 2018-2019)

Figure 8. Graph of Food Environment Score vs Proportion of Students who are Non-Minorities in City Schools 
Suburb Schools: Food Environment Score vs. Proportion of Students that are non-minorities

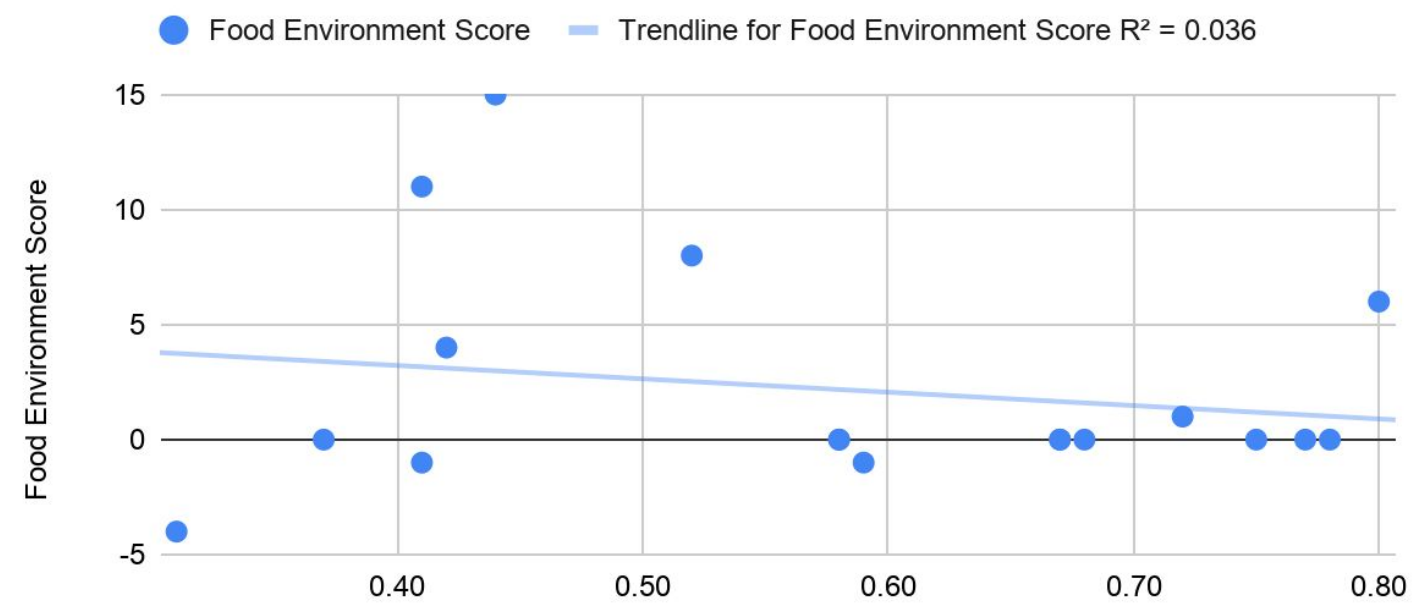

Proportion of Students that are non-minorities (Oregon Department of Education, 2018-2019)

Figure 9. Graph of Food Environment Score vs Proportion of Students who are Non-Minorities in Suburb Schools

Rural/Town Schools: Food Environment Score vs. Proportion of Students that are non-minorities

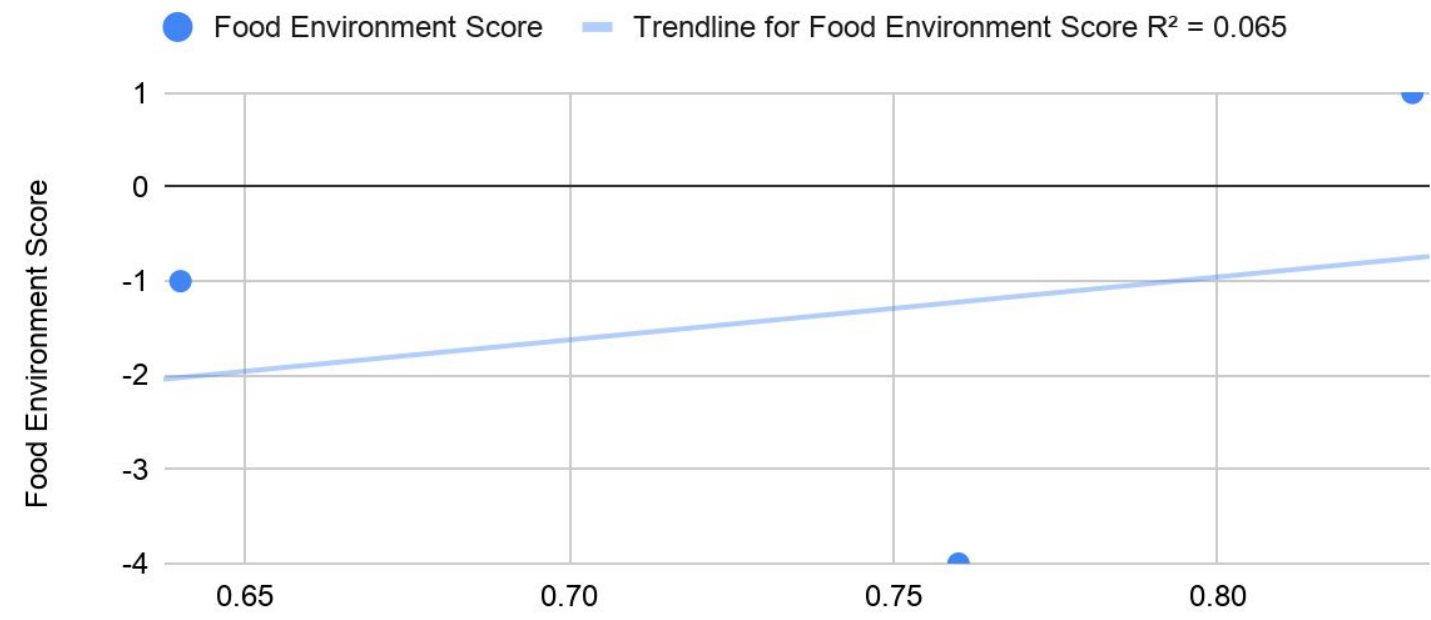

Proportion of Students that are non-minorities (Oregon Department of Education, 2018-2019)

Figure 10. Graph of Food Environment Score vs Proportion of Students who are Non-Minorities in Rural/Town Schools 